\title{
Cognitive performance in UK sample of presymptomatic people carrying the gene for Huntington's disease
}

\author{
L Blackmore, S A Simpson, J R Crawford
}

\begin{abstract}
This paper presents an investigation of cognitive ability in $\mathbf{3 0}$ subjects at risk for Huntington's disease. Those shown to be at high or low risk for this disease are compared on a wide range of neuropsychological measures. Results indicate only one significant difference between the two groups; those who carry the gene show a higher level of performance on the Corsi Supraspan task. It is suggested, however, that minimal deficits are apparent in the at risk gene carrying group but that current measures of assessment are not sensitive enough to identify them.
\end{abstract}

(F Med Genet 1995;32:358-362)

Huntington's disease (HD), described by George Huntington in 1872, is an autosomal dominant neurodegenerative disorder. People with the disease typically present with a choreic movement disorder, personality changes, and a progressive dementia. The age of onset is usually in the fourth or fifth decade, and most patients have offspring by the time the diagnosis is made. These people are at $50 \%$ risk of developing HD. There is evidence that there is a prodromal phase in $\mathrm{HD}$ where subtle but detectable behaviour and mnestic difficulties can be detected. Wilson and Garron ${ }^{1}$ argue that it is possible to show this phase even in pre-adolescence. Research into this area was thought to be of practical use since if evidence for a prodromal phase was found then it could be used as a presymptomatic predictive test. In 1983, Gusella et al found DNA probes linked to the Huntington's locus on chromosome 4 which allowed predictive testing for some families. These tests usually had an accuracy of $95 \%$ or greater. More recently the mutation for this disease has been characterised (Huntington's Disease Collaborative Research Group, $1993^{3}$ ) which offers accurate testing for at risk subjects. The possibility of a prodromal phase is nevertheless of great scientific interest since it may provide improved knowledge of how and at what stage the gene for Huntington's disease begins to manifest itself, and thus could provide further evidence of the mode of action of the mutated gene.

Evidence for a prodromal phase in Huntington's disease has focused on psychometric tests. This is perhaps not surprising since several studies indicate that intellectual deterioration is evident early on in the
Huntington's disease process. Butters $e t a l,{ }^{4}$ for example, note that within one year of diagnosis deficits were detectable in the Digit Symbol and Picture Arrangement subtests of the Wechsler Adult Intelligence Scale (WAIS) and in the Logical Memory and Associate Learning subtests of the Wechsler Memory Scale (WMS). There are clear indications of cognitive decline shortly after diagnosis but the main question in the present context is whether or not these deficits can be detected in those people who carry the gene but who have no classical clinical features of the disease.

Until recent developments in the use of recombinant DNA technology for presymptomatic testing, research into this prodromal phase was restricted to two methodologies. Longitudinal studies were based on administering cognitive tests to at risk subjects and then comparing the results of those who go on to develop Huntington's disease some time later with those who remain symptom free. Using this approach support for the association between cognitive test results and the HD gene became more apparent in the 1970s following publications by Lyle and Quast ${ }^{5}$ and Lyle and Gottesman. ${ }^{67}$ These papers reported a follow up study of 88 at risk subjects, originally assessed by Pearson et $a l^{8}$ as part of the Minnesota Kinship study. Even though assessments took place long before any subjects showed obvious signs of HD, examinations of their results indicated that those 28 at risk subjects who had in fact gone on to develop the disorder showed markedly lower results on the Shipley, Bender Gestalt Recall, and Wechsler Adult Intelligence tests, than did those 60 at risk subjects who did not. This difference was still significant considering only those at risk subjects who had gone on to develop HD six to eight years after original testing. It was also apparent that IQs of those who went on to develop HD averaged 15 points less (1 SD) than did the IQs of those who did not.

These findings were encouraging, supporting the view that psychometric tests could lead to a means of detecting possible deficits in the at risk population. Longitudinal studies, however, do have limitations. There is always a danger that subjects will drop out of such studies or be untraceable at the time of follow up. In the Lyle $e t a b^{-7}$ studies, $50 \%$ of the original sample could not be used in final analysis. Additionally there is always a risk that Huntington's disease could still develop in those at risk subjects classified at follow up as being symptom free, because of the variability of age of onset. 
Test performance of samples of the at risk population as a whole have been compared with normal controls, ${ }^{9-11}$ using a method which avoids the pitfalls of longitudinal study. Fedio et $a l,{ }^{9}$ for example, reported at risk subjects to be significantly impaired on a number of measures, including the Digit Span subtest of the WAIS, Money's Road Map of Directional Sense, and the Stylus Maze Task. Overall studies suggest that deficits in the at risk population are most detectable in the areas of memory, in particular memory recall, in visuospatial abilities, and in tasks sensitive to frontal lobe dysfunction. Results are encouraging but these comparative studies also have a number of problems.

In any sample of the at risk population slightly fewer than half will be gene carriers (since a proportion will have already developed the condition). If differences do exist between those at risk subjects who have the HD gene and normal control subjects, then these differences may be obscured by combining their data with those at risk subjects who do not have the gene. It is also questionable as to whether or not it is valid to compare at risk subjects with normal controls at all. At risk groups as a whole are subject to a different kind of stress not experienced by normal control groups and there is evidence to support the fact that stress can impair cognitive ability. ${ }^{12}$ Very often at risk subjects have the added stress of a parent or grandparent already affected by Huntington's disease. They may also be nervous in the test situation if they believe that the results of cognitive assessments could give an indication as to whether or not they will develop the disorder or confirm fears that they already have the disease.

Since the advent of the presymptomatic test based on DNA analysis an improved research design has been possible. Those at risk people most likely to develop the condition can be compared directly with those least likely to. Comparing at risk groups with each other avoids at least some of the difficulties encountered when comparing at risk subjects with normal controls. First to take advantage of this new research methodology were Jason et al. ${ }^{13}$ The DNA marker used in their study was approximately 95 to $96 \%$ accurate. The researchers, therefore, could be $95 \%$ confident that those in the high risk group $(\mathrm{AR}+)$ did carry the gene while those in the low risk group $(\mathrm{AR}-)$ did not. Comparing performance of these two groups on a large battery of cognitive measures Jason et $a l^{13}$ found that those in the $\mathrm{AR}+$ group had poorer performances on the WMS Visual Recall Test $(p<0 \cdot 02)$, the Wisconsin Card Sorting Test $(\mathrm{p}<0.02)$, the Warrington Dot Discrimination Task $(p<0.02)$, and the two point discrimination threshold for the right palm $(p<0.03)$. Overall deficits in the $A R+$ group were most apparent in the area of visual spatial abilities and in some skills usually associated with cortical lesions to the frontal lobes. General intelligence, motor performance, verbal memory, and language abilities appeared unaffected.

The work of Jason $e t a l^{13}$ looks promising.
However, their conclusions have been carefully scrutinised by Strauss and Brandt ${ }^{14}$ who found that it is premature to conclude that the cognitive differences between the two groups correspond to the presence or absence of the Huntington's gene. Sample sizes in the study were very small, only seven in the AR + group and three in the AR - group. Additionally, all subjects came from only three pedigrees. Differences in cognition could have arisen from genetic influences unrelated to the HD gene. Jason $e t a l^{13}$ also failed to include statistical controls for type 1 errors when analysing their results. Strauss and Brandt ${ }^{14}$ reported new data obtained from a larger pool of subjects, 12 $\mathrm{AR}+, 15 \mathrm{AR}-$, and 15 normal controls included in final analysis. A wide ranging neuropsychological test battery was used but this failed to confirm any of the findings of Jason et al. ${ }^{13}$ None of the differences between AR+ and $A R$ - groups was significant, even at the 0.05 level.

The findings of Strauss and Brandt ${ }^{14}$ are disappointing to those who support the presence of a prodromal phase. However, a more recent study by Diamond et $a l^{15}$ presents a slightly different analysis and resulting conclusion. In the study of Diamond et al, ${ }^{15} 10$ $\mathrm{AR}+$ and eight $\mathrm{AR}$ - subjects were compared on a large battery of tests measuring cognitive ability, including the WAIS-R, WMS, Wisconsin Card Sorting Test, and Trail Making tests. Excluding tests at which subjects performed at ceiling, results of the remaining 19 measures are interpreted in terms of "advantage", with the AR - group being advantaged (that is, with a higher mean performance) on 16 of the tests and the AR+ group being advantaged on only three. Statistical analysis, however, reports only one significant difference, at the $5 \%$ level, between these two groups; AR - subjects performed significantly better on the Paired Associate Learning subtest of the Wechsler Memory Scale. On no other measures of cognitive ability did differences in mean performance reach significance.

Clearly the results of the three studies based on the improved methodology using results based on DNA analysis leave us somewhat sceptical of the presence of a prodromal phase in Huntington's disease, although the references of Diamond et al ${ }^{15}$ to "advantage" suggest it still may be a possibility. The need for further research in this area is evident. To improve validity and power of statistical tests sample sizes must be improved. It is also noticeable that previous studies have entirely depended upon North American samples. The present study investigates cognitive performance of $A R+$ and $A R$ - subjects on a wide range of cognitive measures. Subjects are taken from a sample within the UK.

\section{Methods}

SUBJECTS

All subjects used in the present study were referred by Dr Sheila A Simpson (Department of Medical Genetics, Aberdeen Royal Infirmary 
NHS Trust). The 30 subjects were derived from a larger group of people all of whom had sought a presymptomatic test for Huntington's disease. Subjects were excluded from the study if psychiatric or neurological assessments suggested that they were already affected, or if after counselling they decided they did not wish a result. In each case the presence of Huntington's disease in their family and a suitable family structure for the purpose of DNA testing was confirmed. After cognitive testing had taken place, data from this initial group of 30 was subdivided, for the purpose of analysis, into two further groups, determined by the presence or absence of the Huntington's disease gene, as shown with 98 to $99 \%$ accuracy by linkage analysis. This yielded an AR + group of 13 and an AR - group of 17. The mean age and years of education for the $\mathrm{AR}+$ group were 31.9 (SD 10.3) and 11.7 (SD 2.0) respectively. For the AR - group corresponding figures were 38.5 (SD 11.4) and 11.6 (SD 2.2). Neither of these differences were significant.

All subjects who took part in the study volunteered to do so and all received a small remuneration towards the cost of any expenses incurred. The study obtained the Joint Ethical Committee approval from Grampian Health Board.

PROCEDURE

The neuropsychological test battery administered consisted of a total of 17 tasks, which were divided into three sessions as follows.

Session 1

Wechsler Adult Intelligence Test - Revised. ${ }^{1617}$ National Adult Reading Test. ${ }^{18}$

Session 2

California Verbal Learning Test (CVLT). ${ }^{19}$

Corsi Blocks.

Corsi Block Supraspan. ${ }^{20}$

Table 1 Demographic variables in $A R+$ and $A R-$ groups

\begin{tabular}{llll}
\hline & $A R+$ & $A R-$ & $\begin{array}{l}\text { Significance } \\
(p \text { value })\end{array}$ \\
\hline Age & $31.9(10 \cdot 3)$ & $38.5(11.4)$ & $0 \cdot 108$ \\
Education & $11 \cdot 8(2 \cdot 0)$ & $11 \cdot 6(2 \cdot 2)$ & 0.875 \\
Social class & $3 \cdot 1(0.6)$ & $3 \cdot 1(1.0)$ & 0.951 \\
\hline
\end{tabular}

Table 2 WAIS-R scores in $A R+$ and $A R-$ groups

\begin{tabular}{|c|c|c|c|}
\hline & $A R+$ & $A R-$ & $\begin{array}{l}\text { Significance } \\
\text { ( } p \text { value) }\end{array}$ \\
\hline Full Scale IQ & $96 \cdot 1(12 \cdot 3)$ & $98 \cdot 6(12 \cdot 3)$ & 0.585 \\
\hline Verbal IQ & $95.6(12.5)$ & $98.9(15.5)$ & 0.537 \\
\hline Performance IQ & $97 \cdot 8(14 \cdot 5)$ & $99.8(10.6)$ & 0.671 \\
\hline Information & $8.4(3.0)$ & $8.9(2.9)$ & 0.614 \\
\hline Digit Span & $11 \cdot 0(3 \cdot 3)$ & $10 \cdot 7(3 \cdot 2)$ & 0.807 \\
\hline Vocabulary & $9 \cdot 1(2 \cdot 2)$ & $10 \cdot 4(3 \cdot 1)$ & $0 \cdot 179$ \\
\hline Arithmetic & $10 \cdot 1(3 \cdot 5)$ & $10.5(3.4)$ & 0.803 \\
\hline Comprehension & $8 \cdot 5(2 \cdot 3)$ & $9 \cdot 2(2 \cdot 6)$ & 0.485 \\
\hline Similarities & $9 \cdot 1(2 \cdot 4)$ & $9 \cdot 6(2 \cdot 3)$ & 0.564 \\
\hline Picture Completion & $9 \cdot 9(3 \cdot 2)$ & $9 \cdot 3(2 \cdot 9)$ & 0.586 \\
\hline Picture Arrangement & $9 \cdot 5(3.0)$ & $10 \cdot 8(1 \cdot 8)$ & $0 \cdot 162$ \\
\hline Block Design & $10 \cdot 3(3 \cdot 3)$ & $10 \cdot 3(2 \cdot 6)$ & 0.990 \\
\hline Object Assembly & $9 \cdot 8(3 \cdot 1)$ & $10 \cdot 6(2 \cdot 5)$ & 0.487 \\
\hline Digit Symbol & $8.6(3.7)$ & $9.9(2.2)$ & $0 \cdot 269$ \\
\hline NART Errors & $25 \cdot 7(9 \cdot 3)$ & $19 \cdot 2(11 \cdot 5)$ & $0 \cdot 100$ \\
\hline
\end{tabular}

Digit Supraspan.

Cognitive Estimation Task. ${ }^{21}$

Wisconsin Card Sorting Test - Modified (WCST). ${ }^{22}$

Verbal Fluency. ${ }^{23}$

Purdue Peg Board. ${ }^{24}$

Session 3

Pursuit Rotor. ${ }^{25}$

Benton Visual Retention Test. ${ }^{26}$

Reitan Trails A and B. ${ }^{27}$

Finger Tapping. ${ }^{28}$

Word Completion Task 1 and $2 .{ }^{29}$

Judgement of Line Orientation. ${ }^{30}$

Paced Auditory Serial Addition Task (PASAT). ${ }^{31}$

Items were selected for the test battery because of their known sensitivity to Huntington's disease in affected samples. ${ }^{32}$ Test sessions were restricted to a maximum of one and a half hours in length. It was thought to be inadvisable to make test sessions any longer since subject fatigue could influence performance in tasks later in the session. For all measures standard procedures of administration and scoring were adhered to.

Genetic linkage analyses for the Huntington's disease gene locus were carried out at the Department of Medical Genetics, Aberdeen Royal Infirmary, following a common protocol recommended by the United Kingdom Coordinating Group for Predictive Testing in Huntington's Disease. ${ }^{33}$ Results of the DNA test were not made available to the cognitive test administrator until all cognitive assessments had been completed.

\section{Results}

The DNA test results divided the at risk sample into two groups, with 13 in the $\mathrm{AR}+$ group and 17 in the AR - group. Demographic variables for the two groups are presented in table 1. The mean age for the AR - group (38.5) was somewhat older than that for the AR+ group (31.9), a feature that would be expected given that a proportion of older gene carriers would in fact have developed the condition already. This age difference, however, did not reach statistical significance. Mean years of education for the two groups were 11.8 for the $\mathrm{AR}+$ group and 11.6 for the $\mathrm{AR}$ - group. Again differences did not reach significance.

Results of the psychometric tests were analysed using $t$ tests which compared group means. In order to reduce the possibility of type 1 errors the generally accepted level of significance $(0.05)$ was divided by the number of planned comparisons to reach a new accepted level of significance of $0 \cdot 001$.

Mean data from the cognitive measures for the two groups is presented in tables 2 to 5 . For ease of presentation test results are grouped according to the broad area of functioning being assessed. WAIS-R subtest scores given are age graded.

Tables 2 to 5 show a lack of between group differences in AR + and AR - groups on a wide ranging battery of neuropsychological in- 
Table 3 Executivelattention tasks in $A R+$ and $A R-$ groups

\begin{tabular}{lccl}
\hline & $A R+$ & \multicolumn{1}{c}{$A R-$} & $\begin{array}{l}\text { Significance } \\
(p \text { value })\end{array}$ \\
\hline WCST Correct & $35 \cdot 9(3 \cdot 1)$ & $33 \cdot 7(4 \cdot 0)$ & $0 \cdot 120$ \\
WCST Perseverations & $1 \cdot 1(1 \cdot 4)$ & $1 \cdot 5(3 \cdot 0)$ & $0 \cdot 627$ \\
WCST Categories & $5 \cdot 8(0 \cdot 6)$ & $5 \cdot 3(1 \cdot 1)$ & $0 \cdot 147$ \\
Verbal Fluency F60 & $11 \cdot 8(4 \cdot 5)$ & $11 \cdot 8(4 \cdot 3)$ & $1 \cdot 000$ \\
Verbal Fluency A60 & $8 \cdot 7(3 \cdot 1)$ & $11 \cdot 3(4 \cdot 4)$ & $0 \cdot 082$ \\
Verbal Fluency S60 & $13 \cdot 3(4 \cdot 3)$ & $14 \cdot 4(3 \cdot 8)$ & $0 \cdot 456$ \\
Verbal Fluency Perseverations Total & $0 \cdot 6(1 \cdot 0)$ & $0 \cdot 6(1 \cdot 3)$ & $0 \cdot 961$ \\
Cognitive Estimation Task & $5 \cdot 1(3 \cdot 7)$ & $4 \cdot 8(3 \cdot 5)$ & $0 \cdot 846$ \\
PASAT Total & $147 \cdot 5(49 \cdot 5)$ & $131 \cdot 1(31 \cdot 8)$ & $0 \cdot 352$ \\
PASAT Correct Consecutive Total & $48 \cdot 4(41 \cdot 2)$ & $31 \cdot 2(20 \cdot 2)$ & $0 \cdot 224$ \\
Trail A & $33 \cdot 8(20 \cdot 1)$ & $27 \cdot 0(7 \cdot 7)$ & $0 \cdot 306$ \\
Trail B & $75 \cdot 3(46 \cdot 8)$ & $62 \cdot 2(17 \cdot 3)$ & $0 \cdot 394$ \\
\hline
\end{tabular}

Table 4 Mnestic task performance in $A R+$ and $A R-$ groups

\begin{tabular}{lrrl}
\hline & \multicolumn{1}{c}{$A R+$} & \multicolumn{1}{c}{$A R-$} & $\begin{array}{l}\text { Significance } \\
(p \text { value }\end{array}$ \\
\hline Digit Supraspan & $3 \cdot 2(1 \cdot 7)$ & $3 \cdot 6(2 \cdot 1)$ & $0 \cdot 633$ \\
Corsi Span & $5 \cdot 4(1 \cdot 4)$ & $5 \cdot 9(0 \cdot 9)$ & $0 \cdot 273$ \\
Corsi Supraspan & $2 \cdot 4(0 \cdot 8)$ & $4 \cdot 2(1 \cdot 6)$ & $0 \cdot 001$ \\
CVLT Free Recall List A Long and Short Delay & $22 \cdot 5(7 \cdot 1)$ & $23 \cdot 6(4 \cdot 4)$ & $0 \cdot 654$ \\
CVLT Cued Recall List A Long and Short Delay & $23 \cdot 3(6 \cdot 3)$ & $25 \cdot 3(4 \cdot 7)$ & $0 \cdot 388$ \\
CVLT Intrusions & $4 \cdot 8(4 \cdot 8)$ & $2 \cdot 7(3 \cdot 4)$ & $0 \cdot 221$ \\
CVLT Perseverations & $5 \cdot 9(6 \cdot 9)$ & $6 \cdot 4(7 \cdot 8)$ & $0 \cdot 854$ \\
CVLT Recognition - False Positives & $13 \cdot 7(3 \cdot 1)$ & $14 \cdot 1(1 \cdot 7)$ & $0 \cdot 650$ \\
Word Completion Previously Presented Items & $8 \cdot 7(4 \cdot 5)$ & $9 \cdot 3(3 \cdot 2)$ & $0 \cdot 708$ \\
Benton Visual Retention Test & $11 \cdot 8(3 \cdot 3)$ & $13.5(1 \cdot 6)$ & $0 \cdot 150$ \\
\hline
\end{tabular}

Table 5 Visuospatial and motor task performance in $A R+$ and $A R-$ groups

\begin{tabular}{llll}
\hline & $A R+$ & $A R-$ & $\begin{array}{l}\text { Significance } \\
(p \text { value })\end{array}$ \\
\hline Judgment of Line Orientation Corrected Score & $23 \cdot 2(7 \cdot 6)$ & $24 \cdot 3(2 \cdot 7)$ & $0 \cdot 640$ \\
Purdue Peg Board Total & $116 \cdot 2(18 \cdot 0)$ & $126 \cdot 0(17 \cdot 7)$ & $0 \cdot 168$ \\
Pursuit Rotor Mean Totals & $59 \cdot 7(22 \cdot 1)$ & $48 \cdot 3(10 \cdot 2)$ & $0 \cdot 136$ \\
Pursuit Rotor trials (5+6) - trials (1+2) & $1 \cdot 5(0 \cdot 2)$ & $1 \cdot 9(0 \cdot 5)$ & $0 \cdot 012$ \\
Finger Tapping & $85 \cdot 7(14 \cdot 4)$ & $82 \cdot 1(18 \cdot 1)$ & $0 \cdot 631$ \\
\hline
\end{tabular}

struments. Only one between group difference reached the required level of significance. Paradoxically, that is the difference in Corsi Supraspan, a task at which the AR + group perform better. It is difficult to explain this finding but it is notable that the AR - group have a higher Corsi span (mean 5.9, SD 0.9) than the AR+ group (mean 5.4, SD 1.4). Although this between group difference is not significant, the difference in supraspan scores may reflect a ceiling effect in some $A R$ - subjects.

The above findings suggest that a prodromal phase in Huntington's disease marked by cognitive decline has little experimental backing. This is in accordance with the findings of Strauss and Brandt. ${ }^{14}$ However, if results are interpreted in the manner of Diamond et $a l^{15}$ the position changes. Of the 47 measures the battery contains the AR - group are advantaged in terms of having a higher group mean, albeit insignificant, on 30 and the AR+ group advantaged on only 13. Using $\chi^{2}$ this between group difference is significant at the 0.001 level $\left(\chi^{2}=11.91\right)$. This suggests that mild deficits may be apparent in at risk gene carriers and that tests used in the current battery are not sensitive enough to pick up between group difference.

Previous studies have suggested that deficits in at risk gene carriers are most apparent in mnestic tasks ${ }^{15}$ and in skills associated with frontal lobe dysfunction. ${ }^{13}$ Diamond et $a l^{15}$ argue that the failure of the Strauss and Brandt ${ }^{14}$ study to find between group differences for $\mathrm{AR}+$ and $\mathrm{AR}$ - groups can be explained by the lack of mnestic tasks in their battery. The current study does not support such an argument. Although differences are not significant, the AR - group perform better on the California Verbal Learning Test and Benton Visual Retention Test measures and the AR+ group perform better on the Digit Span tasks and, significantly so, on the Corsi Supraspan task. The current study also does not support findings of early deficits in frontal lobe functioning of AR + subjects. AR + subjects have mean scores which are higher for the Wisconsin Card Sorting Test and the Paced Auditory Serial Addition Test, both tasks which are widely thought to involve significant frontal lobe activity.

\section{Summary}

Data from cognitive test results for at risk subjects in the current study provide little evidence to support the view that cognitive deficits are detectable in asymptomatic gene carriers. Only the Corsi Supraspan task showed a significant difference between groups, and paradoxically at risk gene carriers showed greater ability. However, while individual measures suggest only this between group difference, taken as a whole the study does suggest that minimal dysfunction may be apparent in asymptomatic AR + subjects. Of the 47 measures included in the study, the AR - group are advantaged, in terms of having a higher group mean, on 30 and the $A R+$ group on only 13. It may be that deficits are detectable in individual gene carriers but that current measures of assessment are not sensitive enough to identify them at a group level.

The authors are grateful to the patients who so generously gave their time for this study. Louise Blackmore was funded by the Carnegie Trust for the Universities of Scotland.

1 Wilson RS, Garron DC. Psychological features of Huntington's disease and the problem of early detection. Soc tington's disease and

2 Gusella J, Wexler NS, Conneally PM, et al. A polymorphic DNA marker genetically linked to Huntington's disease. Nature 1983;306:234-8.

3 Huntington's Disease Collaborative Research Group. A novel gene containing a trinucleotide repeat that is expanded and unstable on Huntington's disease chro mosomes. Cell 1993;72:971-83.

4 Butters N, Sax D, Montgomery K, Tarlow S. Comparison of the neuropsychological deficits associated with early and advanced Huntington's disease. Arch Neurol 1978;35 585-9.

5 Lyle OE, Quast W. The Bender Gestalt: use of clinical judgement versus recall scores in predictions of Huntington's disease. F Consult Clin Psychol 1976;44:229-32.

6 Lyle OE, Gottesman II. Premorbid psychometric indicators of the gene for Huntington's disease. 7 Consult Clin Psychol 1977;45:1011-22.

7 Lyle OE, Gottesman II. Subtle cognitive deficits as 15- to 20-year precursors of Huntington's disease. Adv Neurol 1979;23:227-38.

8 Pearson J, Peterson M, Lazaret J, Blodgett H, Kley I. An educational approach to the social problem of Huntington's chorea. Proc Maryland Clinic 1955;30:349-57.

Fedio P, Cox CS, Neophytides A, Canal-Frederick G, Chase TN. Neuropsychological profile of Huntington's disease: patients and those at risk. Adv Neurol 1979;23:239-55. Wexler NS. Perceptual-motor, cognitive and emotional characteristics of persons at-risk for Huntington's disease. Adv
Neurol 1979;23:257-71.

11 Josiassen RC, Curry LM, Mancall EL. Development of neuropsychological deficits in Huntington's disease. Arch Neurol 1983;40:791-6.

12 Seigman AW. The effect of manifest anxiety on a concept formation task and on times and untimed intelligence tests. $\mathcal{F}$ Consult Psychol 1956;20:176-8. 
13 Jason GW, Pajurkova EM, Suchowersky O, et al. Presymptomatic neuropsychological impairment

14 Strauss ME Brandt J Are there neuropsychological manifestations of the nifestations of the gene for Huntington's disease in asympton.

15 Diamond R, White RF, Myers RH, et al. Evidence of presymptomatic cognitive decline in Huntington's disease. presymptomatic cognitive decline in Hunt

16 Wechsler D. WAIS-R manual. New York: Psychological Corporation, 1981.

17 Lea M. A British supplement to the manual for the Wechsler Adult Intelligence Scale - Revised. San Antonio: Psychologica

18 Nelson HE. The National Adult Reading Test (NART): test manual. Windsor: NFER-Nelson, 1982

19 Delis DC, Kramer JH, Kaplan E, Ober BA. CVLT: Califormi Verbal Learning Test. San Antonio: The Psychological Corporation/Harcourt Brace Jovanovich, 1987

20 Milner B. Interhemispheric differences in the localisation of psychological processes in man. Br Med Bull 1971;27: $272-7$

21 Shallice T, Evans ME. The involvement of the frontal lobes in cognitive estimation. Cortex 1980;14:294-303.

22 Nelson HE. A modified card sorting test sensitive to frontal lobe defects. Cortex 1976;12:313-24.
23 Benton AL. Differential behavioural effects in frontal lobe disease. Neuropsychologia 1968;6:53-60.

24 Purdue Research Foundation. Examiner's Manual for the Pundue Peg Board. Chicago: Science Research Associates, 1948.

25 Heindel WC Butters N, Salmon DP. Impaired learning of a motor skill in patients with Huntington's disease. Behav Neurosi 1988;102:141-7.

26 Benton AL. A multiple choice type of the Benton Visual Retention Test. Arch Neurol Psychiatry 1950;64:699-707.

27 Reitan RM. Validity of the trail making test as an indication of organic brain damage. Percep Mot Skills 1958;8:271-6. Reitan RM, Davison LA. Clinical neuropsychology: current Reitan RM, Davison LA. Clinical neuropsychology: curnent

29 Gtatus and applications. New G. The information amnesic patients do not forget, $f$ Exp Psychol (Learn Mem Cog) patients do not

30 Benton AL, Hamsher K, Varney MR, Spreen O. Contributions to neuropsychological assessment. New York: Oxford University Press, 1983.

31 Gronwall DMA, Sampson H. The psychological effects of concussion. Auckland, NZ: Auckland University Press, 1974. 32 Blackmore L. Cognitive deficits in Huntington's disease. $\mathrm{PhD}$ thesis, University of Aberdeen, Scotland, 1993.

33 Simpson SA, Besson J, Alexander J, Allan K, Johnston AW. One hundred requests for predictive testing for Huntington's disease. Clin Genet 1992;41:326-30. 